\title{
Synergistic effect of nanotopography and bioactive ions on peri-implant bone response
}

\author{
This article was published in the following Dove Press journal: \\ International Journal of Nanomedicine \\ 27 January 2017 \\ Number of times this article has been viewed
}

\section{Yingmin $\mathrm{Su}^{\prime}$ \\ Satoshi Komasa' \\ Peiqi $\mathrm{Li}^{2}$ \\ Mariko Nishizaki \\ Luyuan Chen' \\ Chisato Terada' \\ Shigeki Yoshimine' \\ Hiroshi Nishizaki \\ Joji Okazaki'}

'Department of Removable Prosthodontics and Occlusion, ${ }^{2}$ Department of Oral Implantology, Osaka Dental University, Hirakata, Osaka, Japan
Correspondence: Yingmin Su Department of Removable Prosthodontics and Occlusion, Osaka Dental University, 8-I Hanazonocho, Hirakata, Osaka 573-I I 2I, Japan Tel +8I 90 605 I 55I2

Email suyingmin 1987@gmail.com

Peiqi Li

Department of Oral Implantology, Osaka Dental University, 8-I Hanazonocho,

Hirakata, Osaka 573-I I2I, Japan

Tel +8I 8047649012

Email leepeiqiqi@gmail.com

\begin{abstract}
Both bioactive ion chemistry and nanoscale surface modifications are beneficial for enhanced osseointegration of endosseous implants. In this study, a facile synthesis approach to the incorporation of bioactive $\mathrm{Ca}^{2+}$ ions into the interlayers of nanoporous structures (Ca-nano) formed on a Ti6Al4V alloy surface was developed by sequential chemical and heat treatments. Samples with a machined surface and an $\mathrm{Na}^{+}$ion-incorporated nanoporous surface (Na-nano) fabricated by concentrated alkali and heat treatment were used in parallel for comparison. The bone response was investigated by microcomputed tomography assessment, sequential fluorescent labeling analysis, and histological and histomorphometric evaluation after 8 weeks of implantation in rat femurs. No significant differences were found in the nanotopography, surface roughness, or crystalline properties of the Ca-nano and Na-nano surfaces. Bone-implant contact was better in the Ca-nano and Na-nano implants than in the machined implant. The Ca-nano implant was superior to the Na-nano implant in terms of enhancing the volume of new bone formation. The bone formation activity consistently increased for the $\mathrm{Ca}$-nano implant but ceased for the Na-nano implant in the late healing stage. These results suggest that Ca-nano implants have promising potential for application in dentistry and orthopedics.
\end{abstract}

Keywords: surface modification, nanotopography, bioactive ion, osteoinduction, osseointegration

\section{Introduction}

Titanium (Ti) metal and its alloys, such as Ti6Al4V, have been widely used in oral implantology and orthopedic surgery because of their excellent mechanical strength and high biocompatibility. Efforts have been made to develop surface modification techniques to improve the osteoinductive activity of endosseous implants and achieve better osseointegration. ${ }^{1,2}$ Different strategies have been established using commercially available dental implants, including topographic and chemical modifications of their surfaces. ${ }^{3,4}$

Calcium (Ca) ion-incorporated surfaces have been considered beneficial for the behavior of osteoblastic cells and the bone response to Ti implants. ${ }^{5,6} \mathrm{The}^{\mathrm{Ca}}{ }^{2+}$ ion is essential for bone metabolism and stimulates new bone formation, although the detailed mechanisms of this process remain largely unknown. ${ }^{7-9}$ Several procedures have been developed to incorporate $\mathrm{Ca}^{2+}$ ions into metallic substrates. ${ }^{10-12}$ Among the numerous processing methods, hydrothermal treatment is considered as a simple, inexpensive technique with high engineering potential for irregularly shaped implants. The hydrothermal method was utilized to produce a micro-/nanoporous structure enriched with bioactive ions on the Ti surface using an alkali treatment followed by an ion substitution process. ${ }^{13-15}$ In addition, a posterior heat treatment has been shown to improve the scratch resistance and corrosion properties of these bioactive ion-incorporated surfaces. ${ }^{16,17}$ Moreover, a bioactive microporous structure on Ti metal 
and its alloy enriched with $\mathrm{Ca}^{2+}$ ions was fabricated by successive treatment with $\mathrm{NaOH}, \mathrm{CaCl}_{2}$, heat, and water. ${ }^{18,19}$ Both in vitro and in vivo studies have shown high potential of such sequential chemical and heat treatment methods, which can enhance the mechanical property of modified surfaces and bone-bonding ability of bioactive implants. ${ }^{20,21}$

Nanoscale topography has also become a topic of great interest in the surface modification of dental implants. Compared with conventional materials, nanostructured surfaces are able to induce bone cell adhesion, and thus bone cell growth and differentiation, by promoting specific protein interactions. ${ }^{22,23}$ The deposition of nanosized $\mathrm{Ca}$ phosphate (CaP) coatings onto Ti implant surfaces is an interesting modification that mimics the composition and structure of the surrounding bone. ${ }^{24}$ However, CaP coatings have drawbacks such as insufficient mechanical properties of their deposition onto the metallic substrates and bioresorption during biological function. ${ }^{25,26}$ In our previous studies, $\mathrm{Na}^{+}$ ion-incorporated nanoporous structures (Na-nano) produced on Ti metal and Ti6Al4V alloy by an amendatory alkali-heat treatment method had pronounced effects on adhesion and differentiation of osteogenic cells. ${ }^{27-30}$

The bioactive ion chemistry and nanotopography are two significant contributors in the bone response to an implant. However, the synergistic effect of the nanostructure and incorporated bioactive ions on osseointegration remains unclear. In this study, we developed a modified $\mathrm{NaOH}-\mathrm{CaCl}_{2}-$ heat-water treatment method to incorporate $\mathrm{Ca}^{2+}$ ions into a pre-prepared nanoporous structure (Ca-nano) on a Ti6Al4V alloy surface using an amendatory alkali treatment process. The surface characteristics of the resultant nanostructures were analyzed, and an in vivo investigation was performed to compare the bone tissue response between the Ca-nano and Na-nano implants in a rat femur model.

\section{Materials and methods Specimen preparation}

Ti6Al4V disks (15 $\mathrm{mm}$ in diameter and $1 \mathrm{~mm}$ in thickness) and screw implants (1.2 mm in external diameter and $12 \mathrm{~mm}$ in length) prepared by machine (Daido Steel, Osaka, Japan) were used for surface characterization and the animal study, respectively. The following three groups of specimens were prepared: the machined surface group (control group), the Nanano surface group (control group), and the Ca-nano surface group (experimental group). The alloy disks were successively polished with several grades of SiC abrasive paper $(600,800$, 1,000, and 1,500 grits); ultrasonically rinsed using acetone, ethanol, and distilled water for $10 \mathrm{~min}$ each; and dried in air. The disks were immersed in a $10 \mathrm{M} \mathrm{NaOH}$ solution at $30^{\circ} \mathrm{C}$, shaken at a speed of 120 strokes/min for $24 \mathrm{~h}$, and washed with ultrapure water for $30 \mathrm{~s}$ to obtain the nanostructured alloy samples. The $\mathrm{NaOH}$-treated samples were subsequently soaked in $100 \mathrm{mM} \mathrm{CaCl}_{2}$ solution at $40^{\circ} \mathrm{C}$ for $24 \mathrm{~h}$, washed with ultrapure water, and dried overnight. The $\mathrm{NaOH}$-treated and $\mathrm{NaOH}-\mathrm{CaCl}_{2}$-treated samples were subsequently placed in an electrical furnace and heated to $600^{\circ} \mathrm{C}$ at a heating rate of $5^{\circ} \mathrm{C} / \mathrm{min}$, maintained at this temperature for $1 \mathrm{~h}$, and then allowed to naturally cool to room temperature. The $\mathrm{NaOH}-$ $\mathrm{CaCl}_{2}$-heat-treated samples were soaked in $15 \mathrm{~mL}$ of ultrapure water at $80^{\circ} \mathrm{C}$ for $24 \mathrm{~h}$, then washed, and dried.

\section{Surface analysis}

The surface morphology of the alloy samples was examined using scanning electron microscopy (SEM) (S-4800; Hitachi, Tokyo, Japan) with an accelerating voltage of $10 \mathrm{kV}$.

Atomic force microscopy (AFM) (SPM-9600; Shimadzu, Tokyo, Japan) was also performed to obtain the mean average surface roughness ( $\mathrm{Ra}$ ), mean peak-to-valley height (Rz), and two-dimensional surface topography.

The surface chemical compositions of the modified layers were investigated using X-ray photoelectron spectrometry (XPS; PHI X-tool; ULVAC-PHI, Kanagawa, Japan).

X-ray powder diffraction (XRD) (XRD-6100; Shimadzu) was used to determine the surface phase properties. Spectra were recorded in the range of $2 \theta=20^{\circ}-60^{\circ}$, operating at $40 \mathrm{kV}$ and $200 \mathrm{~mA}$ and using a $\mathrm{Cu}-\mathrm{K} \alpha$ radiation source, scanning speed of $2 \% \mathrm{~min}$, and incident angle of $1^{\circ}$.

\section{Animal model and surgical procedures}

The animal experiment was performed in accordance with the ethical guidelines for the Animal Care and Use Committee of Osaka Dental University (admission number: 14-03013) and the study was approved by the Medical Ethics Committee of Osaka Dental University (approval number: 24413). Twenty-four male Sprague-Dawley rats (Shimizu Laboratory Supplies Co., Kyoto, Japan) aged 9 weeks and weighing $180 \pm 18 \mathrm{~g}$ were included in this study. The animals were randomly assigned into three groups of eight rats each. The surgical methods used in this study have been described previously. ${ }^{31}$ Briefly, general anesthesia was induced by intraperitoneal injection of sodium pentobarbital $(0.5 \mathrm{~mL} / \mathrm{kg})$ and local administration of a solution of $0.5 \%$ lidocaine. The skin of the right hind limb was shaved and cleaned with a mixture of iodine and $75 \%$ alcohol solution. A 1-cm-long longitudinal skin incision was made along the medial side of the knee joint, and the subcutaneous fascia was incised. The patella and extensor mechanism were then dislocated to expose the distal aspect of the femur. A pilot hole was 
drilled through the intercondylar notch using a 1-mm-round dental burr under profuse sterile saline irrigation, and the hole was enlarged to $1.2 \mathrm{~mm}$ with an endodontic file. The implants, sterilized by ethylene oxide gas, were randomly inserted into the 24 prepared channels and the medullary cavities of the right femurs. After surgery, the knee joint was restored and the surgical site was closed in layers. The animals received intramuscular injections of gentamicin ( $1 \mathrm{mg} / \mathrm{kg})$ and buprenorphine $(0.05 \mathrm{mg} / \mathrm{kg})$ for 3 days to prevent postsurgical infection and relieve pain. All rats were allowed free movement without any restriction.

\section{Sequential fluorescent labeling}

Polychrome sequential labeling of bone using intraperitoneal injection of fluorochromes was performed to record the process of new bone formation and mineralization after the implantation according to the following schedule: first week, oxytetracycline hydrochloride at $25 \mathrm{mg} / \mathrm{kg}$ (Sigma, St Louis, MO, USA); fourth week, alizarin red S at $30 \mathrm{mg} / \mathrm{kg}$ (Sigma); and eighth week, calcein at $20 \mathrm{mg} / \mathrm{kg}$ (Sigma). All animals were killed by an intraperitoneally injected overdose of sodium pentobarbital 3 days after the final labeling treatment.

\section{Microcomputed tomography assessment}

Immediately after dissection, the right femurs including the implants were kept in cool saline solution and scanned with an SMX-130CT microcomputed tomography (micro-CT) scanner (Shimadzu) operated at $70 \mathrm{kV}$ and $118 \mathrm{~mA}$; the isotropic voxel size was $10 \mu \mathrm{m}$ in all spatial directions. After tomographic acquisitions, the implant and the surrounding tissue were reconstructed and analyzed using morphometric software (TRI/3D-BON; Ratoc System Engineering, Tokyo, Japan). The region of interest (ROI) was defined as the $500 \mu \mathrm{m}$ wide area of bone around the implants from $2 \mathrm{~mm}$ below the highest point of the growth plate to the distal 100 slices. ${ }^{32}$ The bone volume fraction (BV/TV), mean trabecular number (Tb.N), mean trabecular thickness (Tb.Th), and mean trabecular separation (Tb.Sp) were calculated within the ROI.

\section{Histological preparation and histomorphometric analysis}

After the micro-CT scan, the femoral specimens were used to create undecalcified histological sections. The specimens were fixed in $70 \%$ ethanol solution for 7 days followed by immersion in Villanueva bone stain solution. ${ }^{33}$

The femurs were then dehydrated in an ascending series of ethanol (70\%-100\%) and embedded in methyl methacrylate without decalcification. The embedded specimens were sectioned perpendicular to the longitudinal axis of rod-shaped implants. Each specimen was sectioned into $80 \mu \mathrm{m}$ thick slices using a Leica SP1600 saw microtome (Leica, Nussloch, Germany), further ground to $50 \mu \mathrm{m}$ thick sections using a Leica SP2600, and burnished with a polishing machine (MetaServ 2000; Buehler Ltd., Lake Bluff, IL, USA). All sectioning procedures were carried out under running water to maintain a cool temperature. The sections were histomorphometrically analyzed with a BZ-9000 digital microscope (Keyence Co., Osaka, Japan). Fluorescence microscopic evaluation was also performed using a confocal laser scanning microscope (LSM 700; Carl Zeiss, Oberkochen, Germany). The excitation/emission wavelengths of the chelating fluorochromes were 351/460, $543 / 617$, and 488/517 nm for oxytetracycline hydrochloride (blue), alizarin red S (red), and calcein (green), respectively. The region of measurement was defined on sections $\sim 2 \mathrm{~mm}$ below the growth plate to $1 \mathrm{~mm}$ distally according to the micro-CT analysis.

\section{Statistical analyses}

All results are expressed as mean \pm standard deviation and were calculated using Microsoft Excel. The data were analyzed by one-way analysis of variance followed by Student's $t$-test for comparisons between groups. Differences were considered statistically significant at $P<0.05$.

\section{Results}

\section{Surface topography}

Figure 1 shows the SEM and AFM micrographs of the alloy samples with machined surface and modified surfaces. A similar nanosized network morphology was observed on the $\mathrm{Na}$ nano and Ca-nano surfaces. The Ca-nano surface exhibited a finer nanoporous structure (pore size of $30-80 \mathrm{~nm}$ ) than the Na-nano surface (pore size of 50-100 nm). The machined surface had the typical abrasive marks produced by abrasion.

The AFM images showed a similar nanotopography on the Na-nano and Ca-nano surfaces. The values for surface roughness ( $\mathrm{Ra}$ and $\mathrm{Rz}$ ) measured by AFM (Table 1) showed that there were no significant differences between the two nanostructured surfaces.

\section{Surface chemical analyses}

Figure 2 displays the results of the broad-range XPS surface chemical analyses of the Ti6Al4V alloys with machined surfaces and bioactive ion-nanostructured surfaces. The $\mathrm{Na}$ peak was evident in the spectra of the Na-nano surface, while the $\mathrm{Ca}$ peak was detected on the Ca-nano surface. Moreover, no aluminum or vanadium peaks were detected 

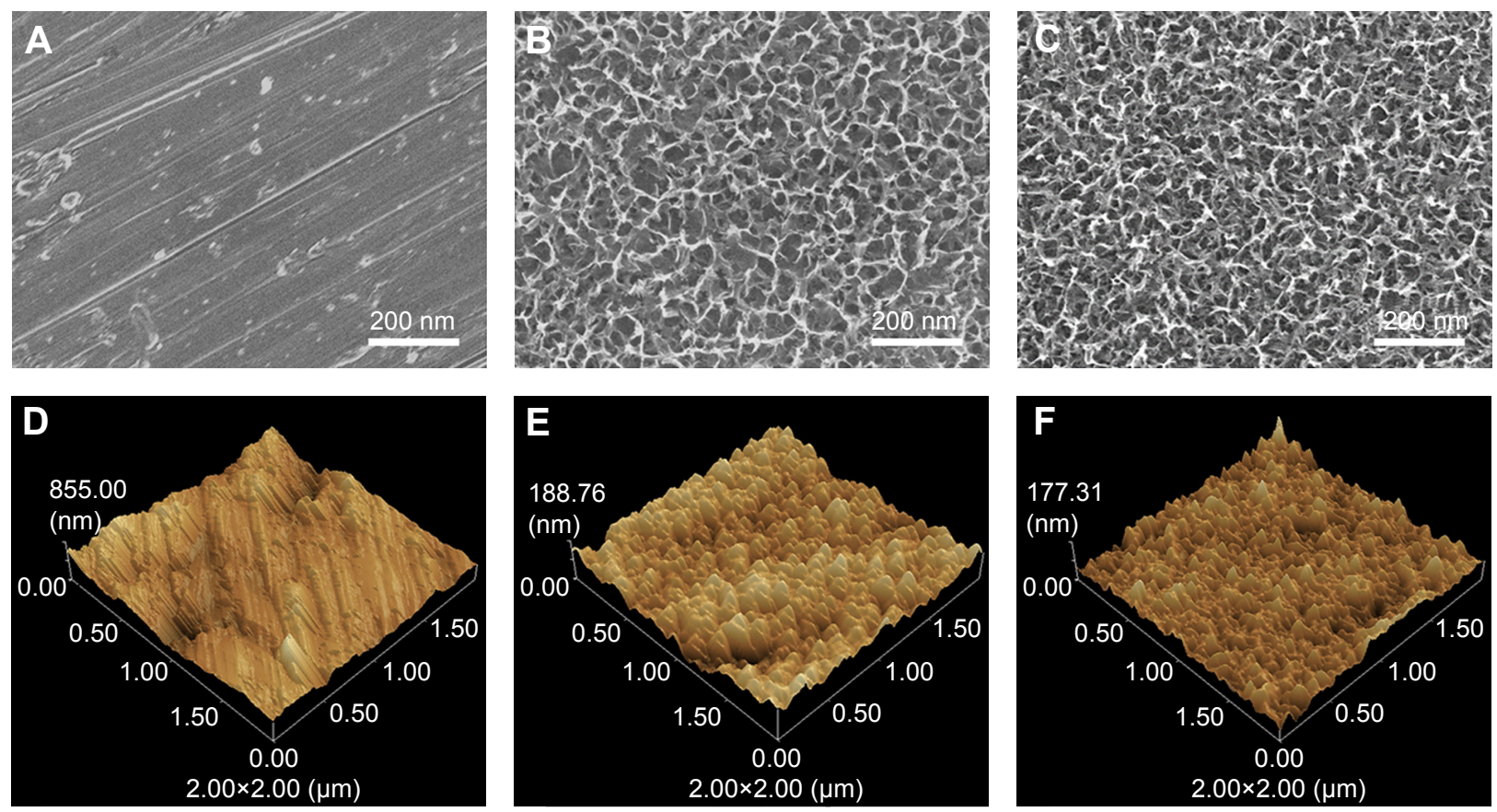

Figure I SEM micrographs and AFM images of specimens with machined and nanostructured surfaces.

Notes: (A and D) Machined surface, (B and E) $\mathrm{Na}^{+}$ion-incorporated nanostructured surface, and $(\mathbf{C}$ and $\mathbf{F}) \mathrm{Ca}^{2+}$ ion-incorporated nanostructured surface.

Abbreviations: AFM, atomic force microscopy; SEM, scanning electron microscopy.

on both nanostructured surfaces. The quantitative surface chemical compositions of the samples are presented in Table 2. Approximately 4.84 atomic percentage (at $\%$ ) $\mathrm{Na}$ was incorporated into the Na-nano surface, while the $\mathrm{Ca}$ content on the Ca-nano surface was $\sim 4.43$ at $\%$.

\section{$X R D$ phase identification}

The XRD profiles in Figure 3 show the crystallographic structures of the Ti6Al4V alloy subjected to various treatments. The broad diffraction peaks detected at $23^{\circ}-29^{\circ}$ and $53^{\circ}$ were attributed to the presence of $\mathrm{Na}$ titanate on the Na-nano surface. The XRD pattern of the Ca-nano surface highly resembled that of the Na-nano surface but contained broad peaks associated with $\mathrm{Ca}$ titanate, such as $\mathrm{CaTi}_{2} \mathrm{O}_{4}$, $\mathrm{CaTi}_{2} \mathrm{O}_{5}$, and $\mathrm{CaTi}_{4} \mathrm{O}_{9}$.

Table I Roughness values of the three different surfaces $(n=8)$

\begin{tabular}{lll}
\hline Group & Parameters & \\
\cline { 2 - 3 } & $\mathbf{R a}(\mathbf{n m})$ & $\mathbf{R z}(\mathbf{n m})$ \\
\hline Machined & $70.25 \pm 4.53^{*, \#}$ & $831.57 \pm 98.46^{*}, \#$ \\
Na-nano & $21.46 \pm 3.14$ & $228.32 \pm 26.75$ \\
Ca-nano & $20.58 \pm 3.02$ & $232.97 \pm 26.92$ \\
\hline
\end{tabular}

Notes: Data are presented as mean \pm standard deviation. $* P<0.05$ vs $\mathrm{Na}$-nano and ${ }^{\#} P<0.05$ vs Ca-nano.

Abbreviations: Ca-nano, $\mathrm{Ca}^{2+}$ ion-incorporated nanostructured surface; Machined, machined surface; $\mathrm{Na}$-nano, $\mathrm{Na}^{+}$ion-incorporated nanostructured surface; $\mathrm{Ra}$, mean average surface roughness; $\mathrm{Rz}$, mean peak-to-valley height.

\section{Micro-CT assessment}

The reconstructed three-dimensional micro-CT images from transverse slices of rat femurs including implants are shown in Figure 4. The implants were marked with red color, the cortical bone was marked with yellow color, and the cancellous bone was marked with green color. Both the Na-nano

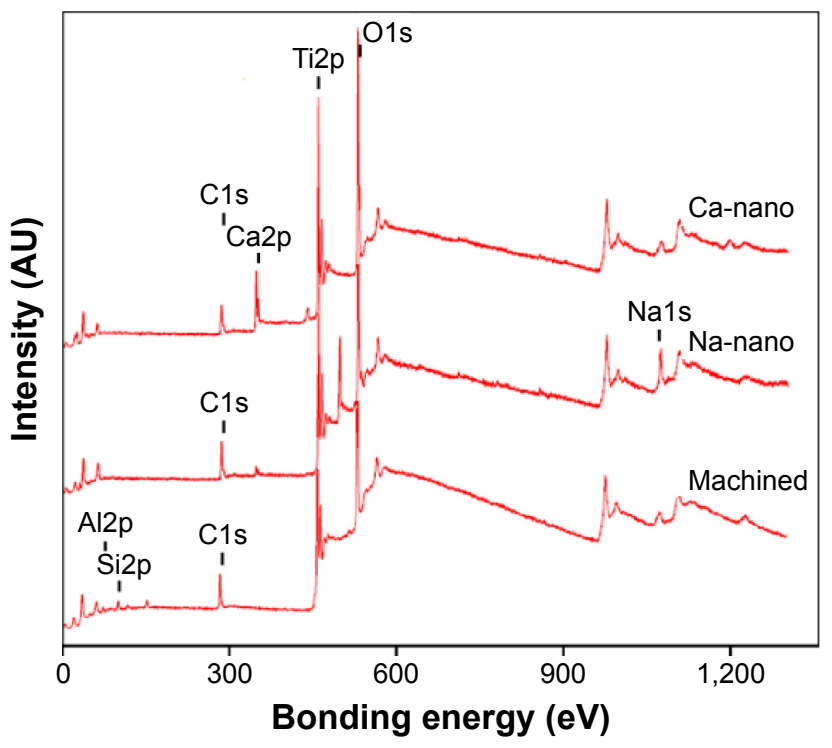

Figure 2 XPS survey spectra of Ti6Al4V alloy specimens with different surfaces. Abbreviations: $\mathrm{AU}$, arbitrary unit; $\mathrm{Ca}$-nano, $\mathrm{Ca}^{2+}$ ion-incorporated nanostructured surface; Machined, machined surface; $\mathrm{Na}$-nano, $\mathrm{Na}^{+}$ion-incorporated nanostructured surface; XPS, X-ray photoelectron spectroscopy. 
Table 2 Surface chemical compositions of specimens examined by XPS $(n=8)$

\begin{tabular}{|c|c|c|c|c|c|c|}
\hline \multirow[t]{3}{*}{ Groups } & \multicolumn{6}{|l|}{ Elements } \\
\hline & \multicolumn{6}{|c|}{ Chemical composition (at\%) } \\
\hline & $\mathrm{Ti}$ & 0 & $\mathrm{Na}$ & $\mathrm{Ca}$ & Al & $\mathbf{v}$ \\
\hline Machined & $25.75 \pm 1.43$ & $65.12 \pm 3.14$ & 0 & 0 & $5.62 \pm 0.56$ & $3.51 \pm 0.29$ \\
\hline Na-nano & $26.42 \pm 1.75$ & $68.74 \pm 3.26$ & $4.84 \pm 0.48$ & 0 & 0 & 0 \\
\hline Ca-nano & $26.38 \pm 1.65$ & $69.13 \pm 3.19$ & 0 & $4.43 \pm 0.32$ & 0 & 0 \\
\hline
\end{tabular}

Note: Data are presented as mean \pm standard deviation.

Abbreviations: at\%, atomic percentage; Ca-nano, $\mathrm{Ca}^{2+}$ ion-incorporated nanostructured surface; Machined, machined surface; $\mathrm{Na}$-nano, $\mathrm{Na}{ }^{+}$ion-incorporated nanostructured surface; XPS, X-ray photoelectron spectroscopy.

surface and Ca-nano surface promoted new bone formation around the implants. More trabecular microarchitecture was observed in the vicinity of the Ca-nano surface than in the vicinity of the Na-nano surface. Quantitative evaluation of the trabecular bone within the ROI is shown in Figure 5 and Table 3. The BV/TV, Tb.N, and Tb.Th were significantly higher in the Ca-nano implants than in the Na-nano and machined implants $(P<0.05$ and $P<0.01$, respectively). $\mathrm{Tb} . \mathrm{Sp}$ was lower in the Ca-nano group $(155.67 \pm 11.17 \mu \mathrm{m})$ than in the control groups.

\section{Histological and histomorphometric evaluation}

The longitudinally undecalcified histological sections with implants and peri-implant bones are presented in Figure 6. Apposition of new bone along the Na-nano and Ca-nano implant surfaces was greater than that along the machined implant surface, where only a small amount of new bone formed. The amount of new bone formation around the

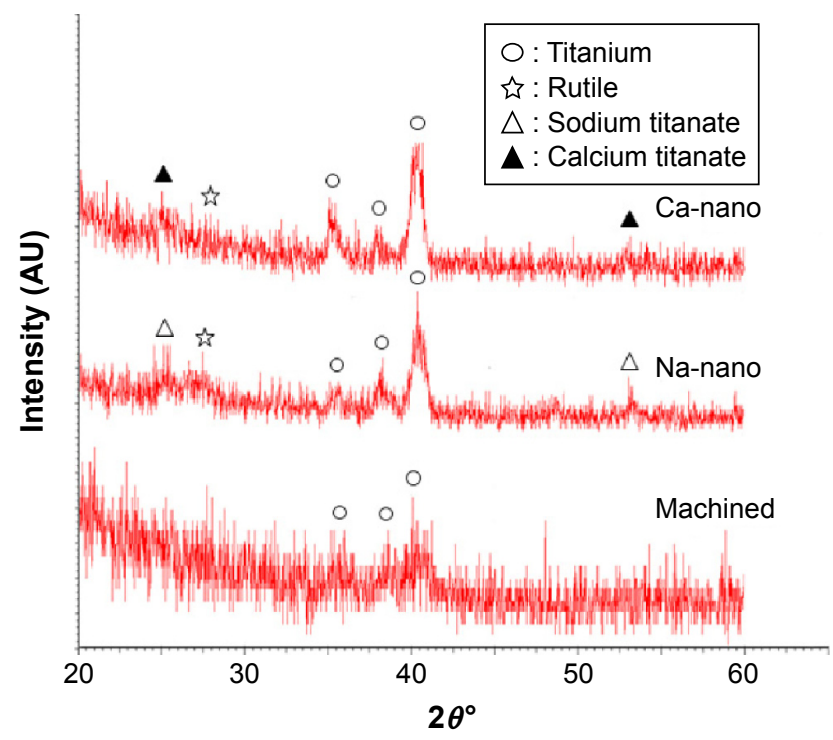

Figure 3 XRD patterns collected from samples with three different surfaces. Abbreviations: $\mathrm{Ca}$-nano, $\mathrm{Ca}^{2+}$ ion-incorporated nanostructured surface; Machined, machined surface; $\mathrm{Na}$-nano, $\mathrm{Na}^{+}$ion-incorporated nanostructured surface; $\mathrm{XRD}$, $\mathrm{X}$-ray powder diffraction.
Na-nano implants was less than that observed in the Ca-nano group. Osteoblasts (osteoblastic osteoid) lining the new bone surface were found on the Ca-nano implant surface at a higher magnification (Figure 6F). Quantitative histomorphometric analysis within the region of measurement above (Figure 7) showed that the new bone area (BA\%) was significantly greater around the Ca-nano implants than around the Na-nano and machined implants $(P<0.05)$. However, there was no significant difference in bone-implant contact (BIC\%) between the Na-nano and Ca-nano implants $(P>0.05)$.

\section{Fluorescence labeling analysis}

The histological sections were also observed using confocal laser scanning microscopy for dynamic histomorphometry according to fluorescence labeling (Figure 8). Three colored lines, namely blue (oxytetracycline hydrochloride, 1 week), red (alizarin red S, 4 weeks), and green (calcein, 8 weeks), were observed in new bone around the implants. The increases in the distance between the implant surface and labeled bone at different time points were significantly higher in the Ca-nano implants than in the Na-nano implants, both of which were significantly higher than those in the machined groups. Quantitatively, the Ca-nano implants exhibited the best effects with regard to an increased percentage of labeled bone area (LBA\%) compared with the control groups $(P<0.05$; Figure 9).

\section{Discussion}

A modified $\mathrm{NaOH}-\mathrm{CaCl}_{2}$-heat-water treatment was performed to construct a bioactive nanoporous surface enriched with $\mathrm{Ca}^{2+}$ ions. In previous studies, the treatment approach involved alkali treatment by $5 \mathrm{M} \mathrm{NaOH}$ solution at $60^{\circ} \mathrm{C}$ followed by $\mathrm{CaCl}_{2}$ immersion and thermal and water treatment to generate a $\mathrm{Ca}^{2+}$ ion-incorporated microporous surface. ${ }^{18}$ This study involved a new modification of this alkali treatment using $10 \mathrm{M} \mathrm{NaOH}$ at $30^{\circ} \mathrm{C}$ to prepare a nanoporous structure on a Ti6Al4V surface. In one study, hydrothermal treatment with a high $\mathrm{CaCl}_{2}$ concentration reportedly destroyed 

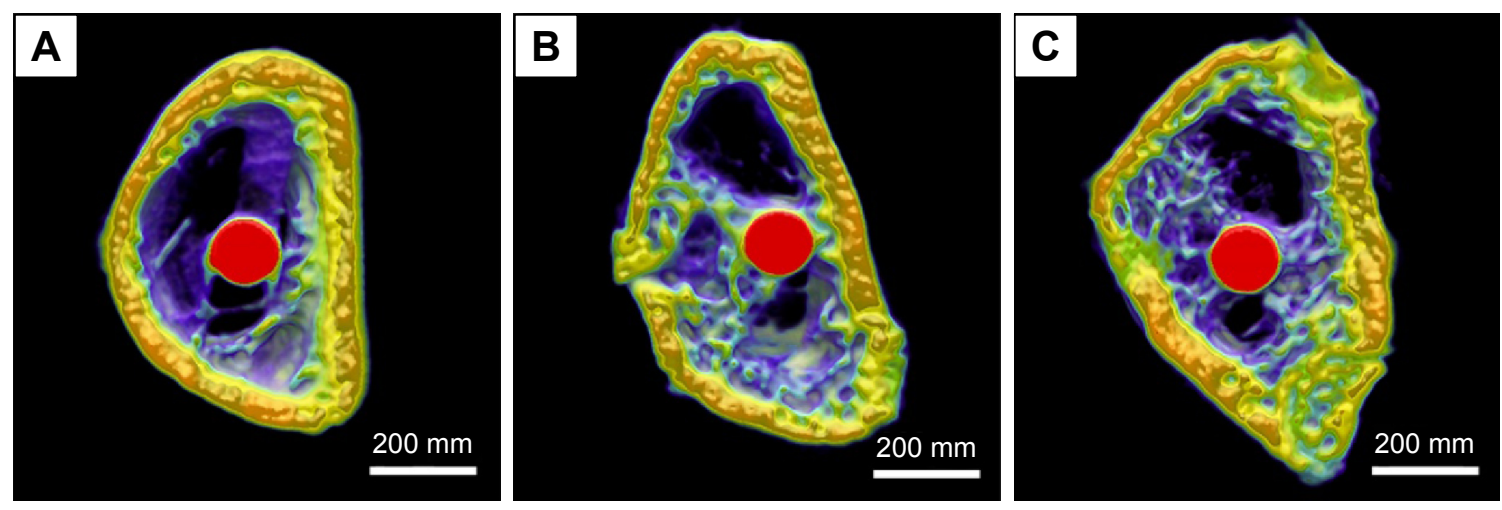

Figure 4 Transverse micro-CT reconstructed images of proximal tibiae showing the status of the Ti6Al4V implant (red) and the response of bone (green) at 8 weeks after implantation.

Notes: (A) Machined surface, (B) $\mathrm{Na}^{+}$ion-incorporated nanostructured surface, and (C) $\mathrm{Ca}^{2+}$ ion-incorporated nanostructured surface.

Abbreviation: CT, computed tomography.

the oxide layer and generated a Ti metal surface without $\mathrm{Ca}^{2+}$ ions, resulting in a decreased apatite formation in the simulated body fluid..$^{34}$ Our surface characterization analysis showed that the incorporation of $\mathrm{Ca}^{2+}$ ions into the nanoporous surface did not alter the nanotopography. This indicates that chloride ion erosion can be negated through application of a $100 \mathrm{mM} \mathrm{CaCl}{ }_{2}$ concentration and that heat treatment

A

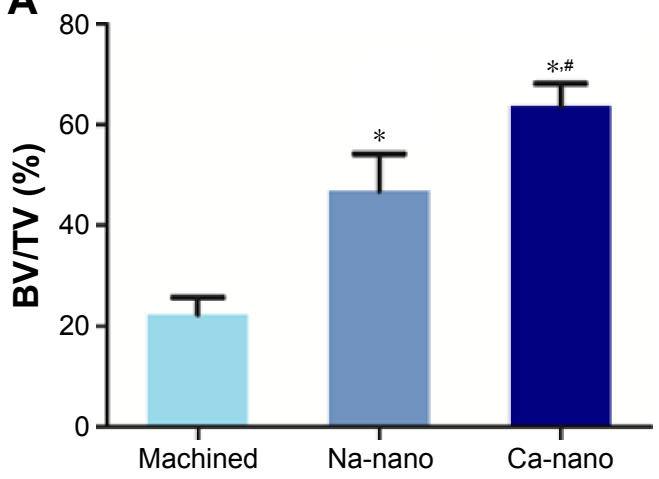

C

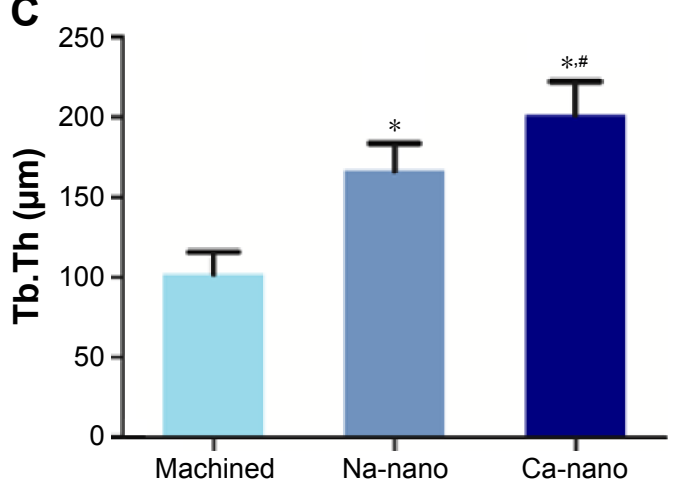

does not have an adverse effect on the nanostructure. No significant differences in the surface roughness or crystalline properties of the Na-nano and Ca-nano surfaces were found, and these can therefore be excluded as reasons for the bone response to the Na-nano and Ca-nano implants.

Ti implants with a $\mathrm{Na}^{+}$ion-incorporated microporous surface produced by alkali and heat treatment are clinically

B

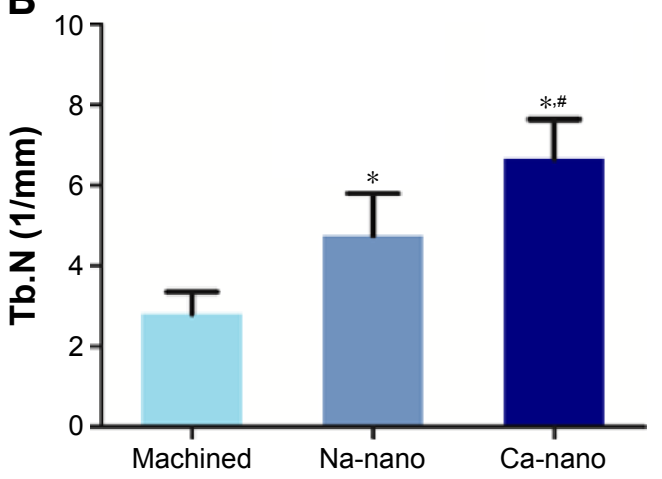

D

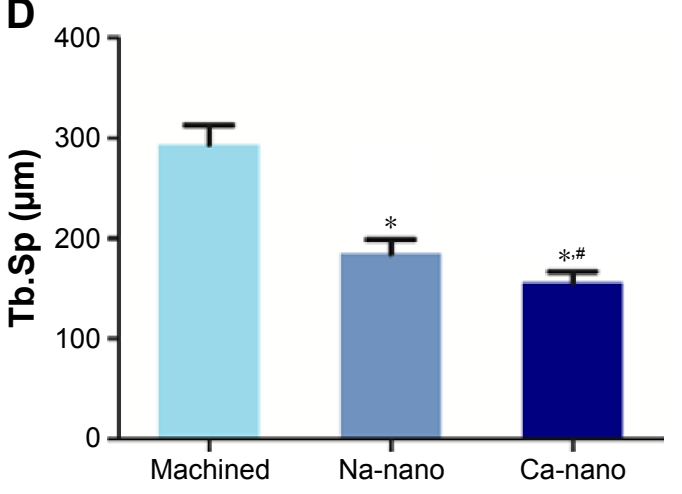

Figure 5 Micro-CT quantitative evaluation within the ROI.

Notes: ${ }^{*} P<0.0$ I vs Machined; ${ }^{*} P<0.05$ vs $\mathrm{Na}$-nano. (A) Bone volume fraction of the three groups, (B) Tb.N of the three groups, (C) Tb.Th of the three groups, and (D) Tb.Sp of the three groups. Error bars represent standard deviation.

Abbreviations: BV/TV, bone volume/total volume; Ca-nano, $\mathrm{Ca}^{2+}$ ion-incorporated nanostructured surface; Machined, machined surface; micro-CT, microcomputed tomography; $\mathrm{Na}$-nano, $\mathrm{Na}^{+}$ion-incorporated nanostructured surface; ROI, region of interest; Tb.N, trabecular number; Tb.Sp, trabecular separation; Tb.Th, trabecular thickness. 
Table 3 Quantification of peri-implant bone formation by microCT analysis $(n=8)$

\begin{tabular}{llll}
\hline Parameters & Groups & & \\
\cline { 2 - 4 } & Machined & Na-nano & Ca-nano \\
\hline BV/TV $(\%)$ & $22.33 \pm 3.35$ & $46.88 \pm 7.31^{*}$ & $63.72 \pm 4.48^{*, \#}$ \\
Tb.N $(1 / \mathrm{mm})$ & $2.82 \pm 0.54$ & $4.75 \pm 1.05^{*}$ & $6.65 \pm 0.99^{*, \#}$ \\
Tb.Th $(\mu \mathrm{m})$ & $102.58 \pm 15.91$ & $171.57 \pm 19.12^{*}$ & $200.50 \pm 22.73^{*, \#}$ \\
Tb.Sp $(\mu \mathrm{m})$ & $290.52 \pm 22.34$ & $182.32 \pm 16.48^{*}$ & $155.67 \pm 11.17^{* . \#}$
\end{tabular}

Notes: Data are presented as mean \pm standard deviation. $* P<0.01$ vs machined and ${ }^{\#} P<0.05$ vs Na-nano.

Abbreviations: BV/TV, bone volume/total volume; $\mathrm{Ca}-n a n o, \mathrm{Ca}^{2+}$ ion-incorporated nanostructured surface; Machined, machined surface; micro-CT, microcomputed tomography; $\mathrm{Na}$-nano, $\mathrm{Na}^{+}$ion-incorporated nanostructured surface; Tb. N, trabecular number; Tb.Sp, trabecular separation; Tb.Th, trabecular thickness.

used in orthopedic applications. ${ }^{35}$ In this study, we fabricated a unique surface that combined a porous nanotopography with bioactive $\mathrm{Na}^{+} / \mathrm{Ca}^{2+}$ ions for obtaining better bone tissue responses to the implants and comparing the enhancement of bioactivity in vivo. It has been demonstrated that a titanate nanostructure incorporated with $\mathrm{Ca}^{2+}$ ions showed superior apatite-forming ability in simulated body fluid and osteogenic function in MC3T3-E1 osteoblast-like cells compared with $\mathrm{Na}^{+}$ions. ${ }^{34,36}$ This study provided the first evidence of enhanced bone volume in the Ca-nano implants compared with that in the Na-nano implants in vivo. The increased amount of new bone formation around the $\mathrm{Ca}$-nano implants may have occurred because the divalent $\mathrm{Ca}^{2+}$ ions provided more binding sites for the polyanions of proteoglycans to bond to the nanostructured surface by electrostatic ionic exchange more effectively than the monovalent $\mathrm{Na}^{+}$ions; as a consequence, osteogenic cells were activated and further bone mineralization was accelerated.

Several in vivo investigations have revealed biologically promising roles of $\mathrm{Ca}^{2+}$ ions. These studies utilized different approaches to incorporate $\mathrm{Ca}^{2+}$ ions into implant surfaces, such as the use of ion implantation or anodic oxidation to prepare Ca-deposited Ti implants and the use of hydrothermal treatment to produce a $\mathrm{CaTiO}_{3}$ layer. ${ }^{37-39}$ Our results showed that formation of a Ca-incorporated oxide layer $\left(\mathrm{CaTi}_{2} \mathrm{O}_{4}\right.$, $\mathrm{CaTi}_{2} \mathrm{O}_{5}$, and $\mathrm{CaTi}_{4} \mathrm{O}_{9}$ ) on the Ti alloy surface by the modified $\mathrm{NaOH}-\mathrm{CaCl}_{2}$-heat-water treatment improved the bone formation in vivo, which is consistent with the findings of previous in vivo studies, although different $\mathrm{Ca}$ products formed on the modified surfaces according to the processing method used.

The bone formation activity around the Ca-nano implant was continuous and substantial up to week 8 in the healing process. In contrast, bone formation activity barely increased around the Na-nano implant and machined implant. Healing at this time point is considered to be in the final stage of wound healing in rat models. ${ }^{40}$ It has been demonstrated that $\mathrm{Ca}^{2+}$ ions might more easily enter the interspaces of the layered structure by electrostatic interaction with the negatively charged $\left(\mathrm{TiO}_{6}\right)_{\mathrm{n}}$ sheet compared with $\mathrm{Na}^{+}$ions. ${ }^{41}$ The more sustained bone formation activity of the Ca-nano implant than that of the Na-nano implant could be attributed to the fact
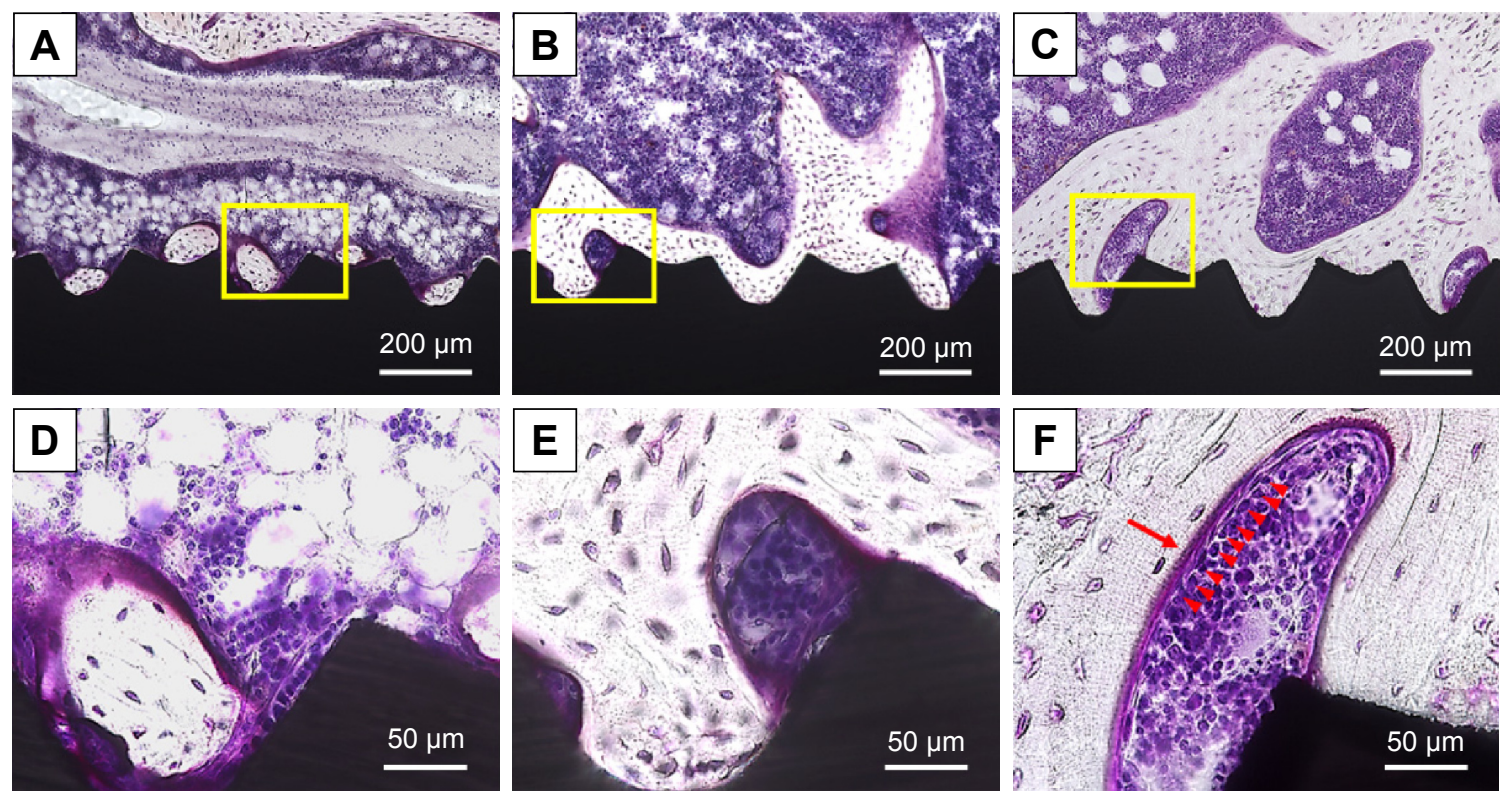

Figure 6 Histological sections with Villanueva bone stain showing the morphology of the bone tissue around the implant (black) at different magnifications.

Notes: Partial magnifications of the yellow rectangular area are displayed in the lower panel. (A and $\mathbf{D})$ Machined surface, (B and $\mathbf{E}) \mathrm{Na}^{+}$ion-incorporated nanostructured surface, and ( $\mathbf{C}$ and $\mathbf{F}) \mathrm{Ca}^{2+}$ ion-incorporated nanostructured surface. Osteoblasts (marked with red triangles) are lining the surface of the osteoid (marked with red arrow). 


\section{A}

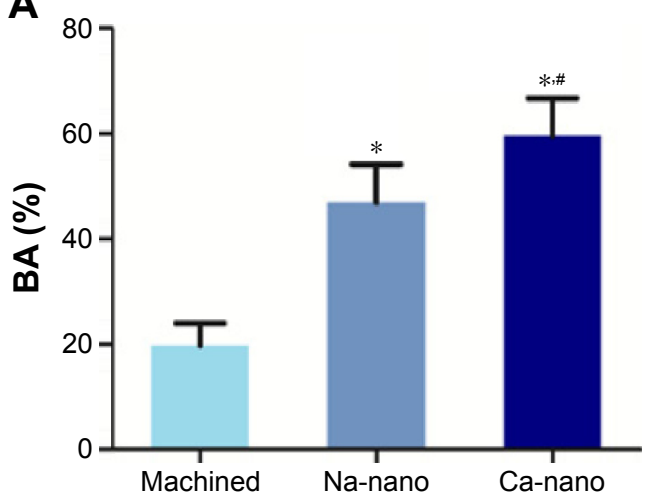

B

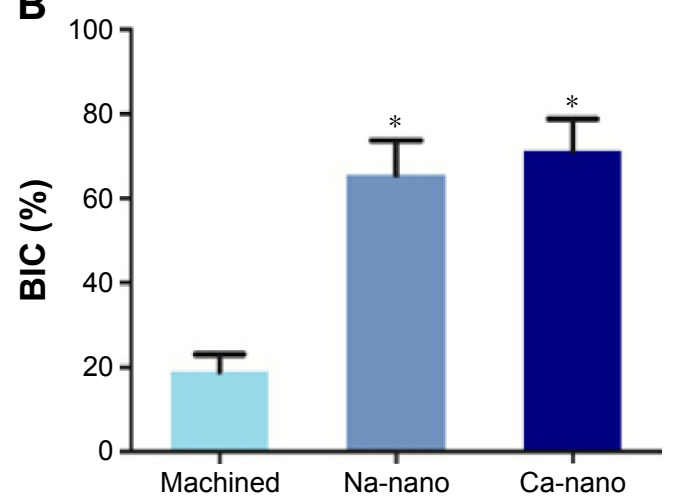

Figure 7 Histomorphometric analysis of peri-implant tissue.

Notes: ${ }^{* P}<0.05$ vs machined and ${ }^{\# P}<0.05$ vs Na-nano. (A) Percentage of new bone formation (BA) and (B) percentage of direct BIC. Error bars represent standard deviation.

Abbreviations: $\mathrm{BA}$, bone area ratio; $\mathrm{BIC}$, bone-implant contact; $\mathrm{Ca}-$ nano, $\mathrm{Ca2}^{+}$ion-incorporated nanostructured surface; Machined, machined surface; $\mathrm{Na}-\mathrm{nano}$, $\mathrm{Na}{ }^{+}$ionincorporated nanostructured surface.

that the $\mathrm{Ca}^{2+}$ ions were incorporated into deeper layers than were the $\mathrm{Na}^{+}$ions and that the ion release rate was controlled by the complex layered nanoporous structure.

The degree of BIC is affected by the early bone response to the implant surface. In this study, the BIC pattern for the Ca-nano implants was not enhanced compared with the Na-nano implants. A previous study showed that a hydroxyapatite-nanostructured surface had no effect on the improvement of BIC compared with a nanostructured surface during the early healing period. ${ }^{42}$ Furthermore, histological and biomechanical studies have shown that the nanotopography is crucial for the acceleration of osseointegration during the early phase of healing. ${ }^{43,44}$ This might indicate that bioactive particles or ions do not have a prominent role in the early bone response to an implant when incorporated into the nanostructured surface. In addition, slower dissolution of $\mathrm{Ca}^{2+}$ than $\mathrm{Na}^{+}$ions from the nanostructure, despite the higher bioactivity of $\mathrm{Ca}^{2+}$ than $\mathrm{Na}^{+}$ions, may explain why we found no evidence of enhanced BIC for the Ca-nano implants.
In this study, a rat femur model was used to evaluate the bone tissue response to implants via only trabecular bone, which is more relevant to the clinical setting. Although this animal model cannot fully simulate the much more complex human situation, it has been proposed and utilized in previous osseointegration studies because the fundamental principles involved in the concept of osseointegration are of significant clinical relevance. ${ }^{45-47}$ Further detailed studies are needed to better understand the potential beneficial effects of bioactive ion-incorporated nanostructured surfaces on osseointegration and biomechanical properties with respect to cortical and corticocancellous bone in larger animals.

\section{Conclusion}

In this study, $\mathrm{Na}^{+}$and $\mathrm{Ca}^{2+}$ ion-incorporated nanoporous structures on Ti6Al4V alloy implants were produced by a facile synthesis approach involving chemical and heat treatments. Both the Ca-nano and Na-nano implants had improved BIC. The Ca-nano implant has advantages over
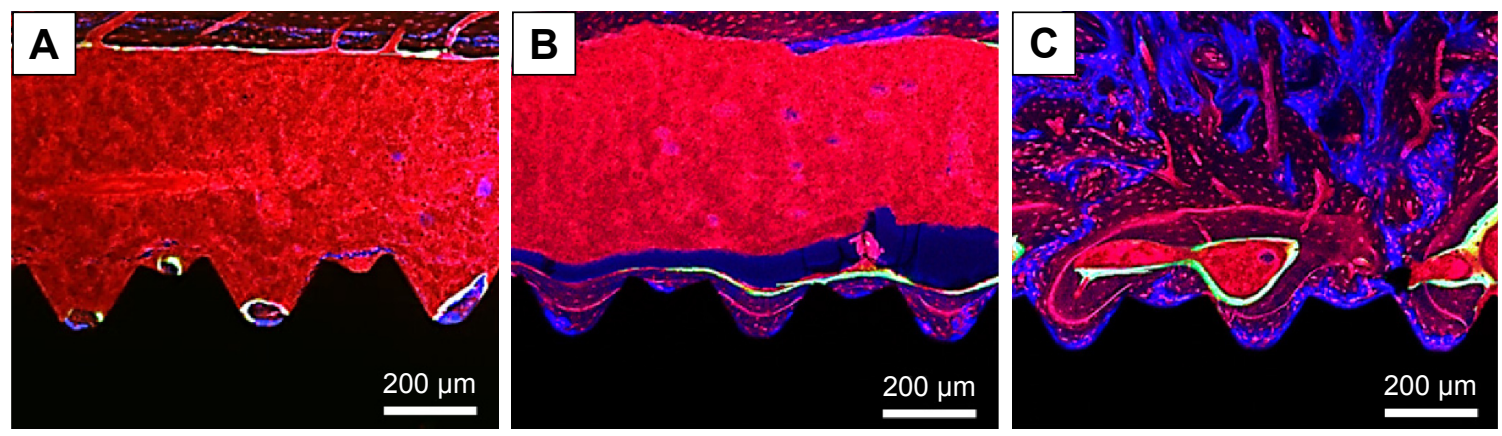

Figure 8 Merged fluorescent images of alloy implants with different surfaces showing blue (oxytetracycline hydrochloride, I week), red (alizarin red S, 4 weeks), and green (calcein, 8 weeks) fluorescent dyes.

Notes: (A) Machined surface, (B) $\mathrm{Na}^{+}$ion-incorporated nanostructured surface, and (C) $\mathrm{Ca}^{2+}$ ion-incorporated nanostructured surface. 
A

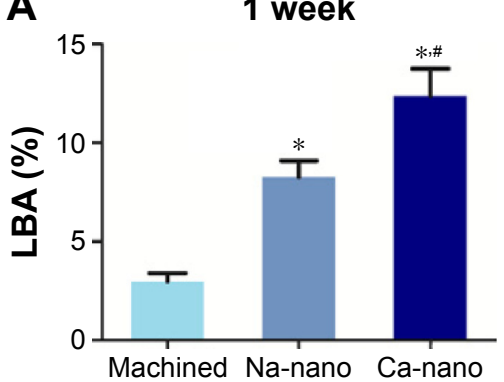

B

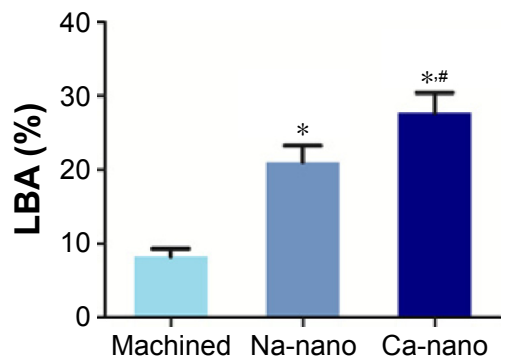

C

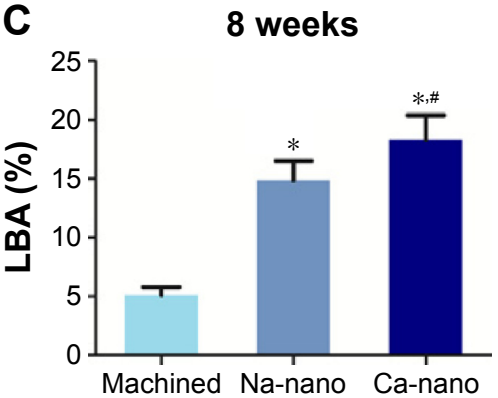

Figure 9 Fluorescence labeling analysis of new bone formation at (A) I week, (B) 4 weeks, and (C) 8 weeks after implantation.

Notes: $* P<0.05$ vs Machined and ${ }^{*} P<0.05$ vs Na-nano. Error bars represent standard deviation.

Abbreviations: Ca-nano, $\mathrm{Ca}^{2+}$ ion-incorporated nanostructured surface; $\mathrm{LBA}$, labeled bone area; Machined, machined surface; $\mathrm{Na}$-nano, $\mathrm{Na}{ }^{+}$ion-incorporated nanostructured surface.

the Na-nano implant with respect to the amount of new bone formation and degree of sustained osteoinductive activity; these benefits were ascribed to the nanostructured surface with the controllable release properties of the $\mathrm{Ca}^{2+}$ ions. Nanostructure modification with incorporation of $\mathrm{Ca}^{2+}$ ions has a synergistic effect on the bone response to the implant. Therefore, this technique exhibits the potential for application in the fields of dentistry and orthopedics.

\section{Acknowledgments}

This study was supported by a grant from the Japan Society for the Promotion of Science (16K20524) and an Oral Implant Research Grant of Osaka Dental University (16-02). We would like to thank the Ito Bone Histomorphometry Institute for their help in the histological preparation.

\section{Disclosure}

The authors report no conflicts of interest in this work.

\section{References}

1. Duraccio D, Mussano F, Faga MG. Biomaterials for dental implants: current and future trends. J Mater Sci. 2015;50(14):4779-4812.

2. Shibata Y, Tanimoto Y. A review of improved fixation methods for dental implants. part I: surface optimization for rapid osseointegration. J Prosthodont Res. 2015;59(1):20-33.

3. Wennerberg A, Jimbo R, Albrektsson T. Implant surfaces and their biological and clinical impact. Implant Surfaces and their Biological and Clinical Impact. Springer, Berlin Heidelberg; 2015.

4. Jemat A, Ghazali MJ, Razali M, Otsuka Y. Surface modifications and their effects on titanium dental implants. Biomed Res Int. Vol 2015;2015.

5. Nayab SN, Jones FH, Olsen I. Human alveolar bone cell adhesion and growth on ion-implanted titanium. J Biomed Mater Res A. 2004;69(4):651-657.

6. Fröjd V, Franke-Stenport V, Meirelles L, Wennerberg A. Increased bone contact to a calcium-incorporated oxidized commercially pure titanium implant: An in-vivo study in rabbits. Int J Oral Maxillofac Surg. 2008;37(6):561-566.

7. Rautray TR, Narayanan R, Kwon TY, Kim KH. Surface modification of titanium and titanium alloys by ion implantation. $J$ Biomed Mater Res Part B Appl Biomater. 2010;93(2):581-591.

8. Nayab S, Shinawi L, Hobkirk J, Tate TJ, Olsen I, Jones FH. Adhesion of bone cells to ion-implanted titanium. J Mater Sci Mater Med. 2003; 14(11):991-997.
9. Zhang L, Ayukawa Y, LeGeros RZ, Matsuya S, Koyano K, Ishikawa K. Tissue-response to calcium-bonded titanium surface. J Biomed Mater Res A. 2010;95(1):33-39.

10. Nayab SN, Jones FH, Olsen I. Modulation of the human bone cell cycle by calcium ion-implantation of titanium. Biomaterials. 2007;28(1): $38-44$

11. Chen X, Li YC, Du Plessis J, Hodgson PD, Wen C. Influence of calcium ion deposition on apatite-inducing ability of porous titanium for biomedical applications. Acta Biomater. 2009;5(5):1808-1820.

12. Ribeiro AR, Oliveira F, Boldrini LC, et al. Micro-arc oxidation as a tool to develop multifunctional calcium-rich surfaces for dental implant applications. Mater Sci Eng C Mater Biol Appl. 2015;54:196-206.

13. Ren N, Li J, Qiu J, et al. Nanostructured titanate with different metal ions on the surface of metallic titanium: a facile approach for regulation of rBMSCs fate on titanium implants. Small. 2014;10(15):3169-3180.

14. Sawada R, Kono K, Isama K, Haishima Y, Matsuoka A. Calciumincorporated titanium surfaces influence the osteogenic differentiation of human mesenchymal stem cells. J Biomed Mater Res A. 2013;101 A(9): 2573-2585.

15. Rakngarm A, Miyashita Y, Mutoh Y. Formation of hydroxyapatite layer on bioactive ti and ti-6Al-4V by simple chemical technique. J Mater Sci Mater Med. 2008;19(5):1953-1961.

16. Li B, Zhang K, Yang W, Yin X, Liu Y. Enhanced corrosion resistance of HA/CaTiO3/TiO2/PLA coated AZ31 alloy. J Taiwan Inst Chem Eng. 2016;59:465-473.

17. Laurindo CAH, Bemben LM, Torres RD, Mali SA, Gilbert JL, Soares P. Influence of the annealing treatment on the tribocorrosion properties of ca and $\mathrm{P}$ containing $\mathrm{TiO} 2$ produced by plasma electrolytic oxidation. Mater Technol. 2016;31(12):719-725.

18. Kizuki T, Takadama H, Matsushita T, Nakamura T, Kokubo T. Preparation of bioactive Ti metal surface enriched with calcium ions by chemical treatment. Acta Biomater. 2010;6(7):2836-2842.

19. Yamaguchi S, Kizuki T, Takadama H, Matsushita T, Nakamura T, Kokubo T. Formation of a bioactive calcium titanate layer on gum metal by chemical treatment. J Mater Sci Mater Med. 2012;23(4):873-883.

20. Yamaguchi S, Takadama H, Matsushita T, Nakamura T, Kokubo T. Apatite-forming ability of ti-15Zr-4Nb-4Ta alloy induced by calcium solution treatment. J Mater Sci Mater Med. 2010;21(2):439-444.

21. Fukuda A, Takemoto M, Saito T, et al. Bone bonding bioactivity of ti metal and ti-zr-nb-ta alloys with ca ions incorporated on their surfaces by simple chemical and heat treatments. Acta Biomater. 2011;7(3): 1379-1386.

22. Song Y, Ju Y, Morita Y, Song G. Effect of the nanostructure of porous alumina on growth behavior of MG63 osteoblast-like cells. J Biosci Bioeng. 2013;116(4):509-515.

23. Li X, Wang L, Fan Y, Feng Q, Cui FZ, Watari F. Nanostructured scaffolds for bone tissue engineering. J Biomed Mater Res A. 2013;101 A(8): 2424-2435. 
24. Liao SS, Cui FZ, Zhang W, Feng QL. Hierarchically biomimetic bone scaffold materials: nano-HA/collagen/PLA composite. J Biomed Mater Res B Appl Biomater. 2004;69(2):158-165.

25. Wang H, Eliaz N, Xiang Z, Hsu HP, Spector M, Hobbs LW. Early bone apposition in vivo on plasma-sprayed and electrochemically deposited hydroxyapatite coatings on titanium alloy. Biomaterials. 2006;27(23): 4192-4203.

26. Mohseni E, Zalnezhad E, Bushroa AR. Comparative investigation on the adhesion of hydroxyapatite coating on ti-6Al-4V implant: a review paper. Int J Adhes Adhes. 2014;48:238-257.

27. Komasa S, Taguchi Y, Nishida H, Tanaka M, Kawazoe T. Bioactivity of nanostructure on titanium surface modified by chemical processing at room temperature. J Prosthodont Res. 2012;56(3):170-177.

28. Komasa S, Kusumoto T, Taguchi Y, et al. Effect of nanosheet surface structure of titanium alloys on cell differentiation. J Nanomater. Vol 2014;2014

29. Su Y, Komasa S, Sekino T, Nishizaki H, Okazaki J. Characterization and bone differentiation of nanoporous structure fabricated on Ti6Al4V alloy. J Nanomater. Vol 2015;2015.

30. Su Y, Komasa S, Sekino T, Nishizaki H, Okazaki J. Nanostructured Ti6A14V alloy fabricated using modified alkali-heat treatment: characterization and cell adhesion. Mater Sci Eng C. 2016;59:617-623.

31. Li X, Li Y, Peng S, Ye B, Lin W, Hu J. Effect of zinc ions on improving implant fixation in osteoporotic bone. Connect Tissue Res. 2013;54(4-5): 290-296.

32. Li Y, Li X, Song G, Chen K, Yin G, Hu J. Effects of strontium ranelate on osseointegration of titanium implant in osteoporotic rats. Clin Oral Implants Res. 2012;23(9):1038-1044.

33. Kweon H, Lee SW, Hahn BD, Lee YC, Kim SG. Hydroxyapatite and silk combination-coated dental implants result in superior bone formation in the peri-implant area compared with hydroxyapatite and collagen combination-coated implants. J Oral Maxillofac Surg. 2014;72(10): 1928-1936.

34. Nakagawa M, Zhang L, Udoh K, Matsuya S, Ishikawa K. Effects of hydrothermal treatment with $\mathrm{CaCl} 2$ solution on surface property and cell response of titanium implants. J Mater Sci Mater Med. 2005;16(11): 985-991.

35. Kawanabe K, Ise K, Goto K, et al. A new cementless total hip arthroplasty with bioactive titanium porous-coating by alkaline and heat treatment: average 4.8-year results. J Biomed Mater Res B Appl Biomater. 2009; $90 \mathrm{~B}(1): 476-481$.
36. Ogawa T, Ozawa S, Shih JH, et al. Biomechanical evaluation of osseous implants having different surface topographies in rats. J Dent Res. 2000; 79(11):1857-1863

37. Jinno T, Kirk SK, Morita S, Goldberg VM. Effects of calcium ion implantation on osseointegration of surface-blasted titanium alloy femoral implants in a canine total hip arthroplasty model. J Arthroplasty. 2004; 19(1):102-109

38. Gao Y, Gao B, Wang R, et al. Improved biological performance of low modulus ti-24Nb-4Zr-7.9Sn implants due to surface modification by anodic oxidation. Appl Surf Sci. 2009;255(9):5009-5015.

39. Park JW, Park KB, Suh JY. Effects of calcium ion incorporation on bone healing of Ti6Al4V alloy implants in rabbit tibiae. Biomaterials. 2007;28(22):3306-3313.

40. Wang T, Wan Y, Liu Z. Synergistic effects of bioactive ions and micro/ nano-topography on the attachment, proliferation and differentiation of murine osteoblasts (MC3T3). J Mater Sci Mater Med. 2016; 27(8):1-12.

41. Kizuki T, Takadama H, Matsushita T, Nakamura T, Kokubo T. Effect of ca contamination on apatite formation in a ti metal subjected to $\mathrm{NaOH}$ and heat treatments. J Mater Sci Mater Med. 2013;24(3):635-644.

42. Meirelles L, Melin L, Peltola T, et al. Effect of hydroxyapatite and titania nanostructures on early in vivo bone response. Clin Implant Dent Relat Res. 2008;10(4):245-254.

43. Bjursten LM, Rasmusson L, Oh S, Smith GC, Brammer KS, Jin S. Titanium dioxide nanotubes enhance bone bonding in vivo. J Biomed Mater Res A. 2010;92(3):1218-1224.

44. Jimbo R, Coelho PG, Vandeweghe S, et al. Histological and threedimensional evaluation of osseointegration to nanostructured calcium phosphate-coated implants. Acta Biomater. 2011;7(12):4229-4234.

45. Li Y, Qi Y, Gao Q, et al. Effects of a micro/nano rough strontium-loaded surface on osseointegration. Int J Nanomed. 2015;10:4549-4563.

46. Dang $\mathrm{Y}$, Zhang L, Song W, et al. In vivo osseointegration of ti implants with a strontium-containing nanotubular coating. Int J Nanomed. 2016; 11:1003-1011.

47. Abron A, Hopfensperger M, Thompson J, Cooper LF. Evaluation of a predictive model for implant surface topography effects on early osseointegration in the rat tibia model. J Prosthet Dent. 2001; 85(1):40-46.
International Journal of Nanomedicine

\section{Publish your work in this journal}

The International Journal of Nanomedicine is an international, peerreviewed journal focusing on the application of nanotechnology in diagnostics, therapeutics, and drug delivery systems throughout the biomedical field. This journal is indexed on PubMed Central, MedLine, CAS, SciSearch ${ }^{\circledR}$, Current Contents ${ }^{\circledR} /$ Clinical Medicine,

\section{Dovepress}

Journal Citation Reports/Science Edition, EMBase, Scopus and the Elsevier Bibliographic databases. The manuscript management system is completely online and includes a very quick and fair peer-review system, which is all easy to use. Visit http://www.dovepress.com/ testimonials.php to read real quotes from published authors. 